\title{
Perceptions of Indian women on hysterectomy
}

\author{
Shuchi Jain, Shruti S. Pansare* \\ Department of Obstetrics and Gynaecology, Mahatma Gandhi Institute of Medical Sciences, Maharashtra India
}

Received: 25 August 2017

Accepted: 09 September 2017

\section{*Correspondence:}

Dr. Shruti S. Pansare,

E-mail: shrutispansare@gmail.com

Copyright: (c) the author(s), publisher and licensee Medip Academy. This is an open-access article distributed under the terms of the Creative Commons Attribution Non-Commercial License, which permits unrestricted non-commercial use, distribution, and reproduction in any medium, provided the original work is properly cited.

\section{ABSTRACT}

Background: Women who undergo hysterectomy face a multitude of physical and psychosocial problems. The objective of the study was to assess the impact of pre-operative education on post-operative psychosocial health.

Methods: It was an interventional research in 96 women who were randomly divided into two groups; one received pre-operative education about surgery and the other given routine preoperative advice. With the help of a questionnaire the perceptions of women on hysterectomy were assessed.

Results: Post-operation, 47 of the intervened patients and all the patients of control group were satisfied with the surgery, statistically insignificant; fisher's exact of 1 . For 20 intervened patients and 6 patients of control group were very acceptable with the fact that the uterus was no longer present in the body post-surgery, statistically significant; fisher's exact of 0.001. 45 of the intervened group were not feeling depressed whereas 19 patients of the control group were feeling depressed, statistically significant; fisher's exact of 0.0005 .

Conclusions: Thus, there was a positive impact of pre-operative education on perceptions about hysterectomy. Women who underwent hysterectomy after receiving preoperative education were content with the results of surgery. Resuscitation in preeclampsia. Acute fetal distress in labour or neonatal nursery admission could not be predicted.

Keywords: Hysterectomy, Perception, Preoperative education, Postoperative perception

\section{INTRODUCTION}

With the development of less invasive treatments, the suitability of hysterectomy as a treatment for benign symptoms is being re-evaluated. ${ }^{1,2}$ The procedure is accompanied with various psychosocial effects in terms of pain experienced, sexual functioning and pre-operative as well as post-operative anxiety. Surgery can be physically and psychologically stressful for patients

Moreover, there is very less research done in patients undergoing elective hysterectomy in rural areas of India. There are various aspects of this surgery that affect patient's health. Most of these aspects are related to the knowledge of the patient about the surgery and its outcomes. The psychological, physical and sexual impacts of hysterectomy are conflicting and the findings are mixed. ${ }^{3}$ While some studies report that patients have experienced greater improvement in their mental health, sexual desire and functioning, and overall satisfaction, others show that patients report various negative outcomes, with ill effects on sexual functioning being the main concern. ${ }^{5,6}$

The knowledge pertaining to the surgery in patients of rural setting is very low, especially in developing country like India. Women who undergo hysterectomy surgery face a multitude of physical and psychosocial problems both before and after the hysterectomy. ${ }^{7}$ There are various aspects like anxiety; both pre-and post-operative, familiar support, social misconceptions, psychological aspects. While it is established that side-effects of hysterectomy include both positive and negative physical or emotional aspects, there have been no studies examining these effects among Indian rural women., ${ }^{8,9}$ Therefore, there is a need to study the level of knowledge 
in such patients and then to assess their problems in terms of anxiety, psychosocial behavioural changes and acceptance for undergoing the surgery.

\section{METHODS}

It was a randomized control trial. Population involved was that in rural part of Central India. Study was carried out in a rural hospital in Central India.

\section{Inclusion criteria}

- Patients in the age group of 38-70 years

- Patients undergoing hysterectomy for benign conditions

- Patients willing to be part of study

- Patients who can understand and comprehend.

\section{Exclusion criteria}

- Patients undergoing surgery for malignant conditions

- Patients suffering from psychiatric disorder

- Patients suffering from chronic pain

Women were sorted in two groups, the intervened and control group by providing them a random number either 1 or 2 (1=intervened; $2=$ control). Written informed consent was obtained from all participants who showed interest in the study. Participants were assured that their responses would be confidential and reminded that their participation in the interview was voluntary. Only those candidates were selected who would undergo surgery the very next day.

Accordingly, intervened group was given basic information about the surgery by a verbal counseling session; the control group was given basic care. Then, women of both the groups were asked certain questions enquiring about socio economic status, their views about the surgery pre-operatively. Post operatively, they were asked about their perception regarding pain and psychological effect of surgery.

The data thereby collected was subjected to analysis. SPSS software was used to analyze the data. The results regarding their perception were unbiased as the baseline variables were matched for both groups.

\section{RESULTS}

All together 96 patients took part in the study. Mean age in the intervened group was 46 (standard error of 1.31) and in control groups was 47.5 (standard error $=1.44$ ). Mean education of the intervened group was 6.17 and control group was 5.79 class of schooling. Mean age of menarche was 13.98 in intervened group and 14.13 in control group and mean age of menopause in the intervened group was 49.88, and control group 49.82. Total of only 19 patients were post-menopausal. The above data is tabulated in Table 1 . There is no variation in the baseline variables. The occupation of the patients as categorized in Figure 1. Majority of the patients were housewives i.e. $52.08 \%$.

Table 1: Mean values for demographic factors.

\begin{tabular}{|lll|}
\hline Demographic factors- with std. error (total observations 96) & Intervention & Control \\
\hline Mean age & $46(1.312)$ & $47.5(1.438)$ \\
\hline Mean age of menarche & $13.98(0.203)$ & $14.13(0.205)$ \\
\hline Mean age of menopause (total observations -19) & $49.88(2.601)$ & $49.82(1.174)$ \\
\hline Mean education & $6.17(0.624)$ & $5.79(0.639)$ \\
\hline
\end{tabular}

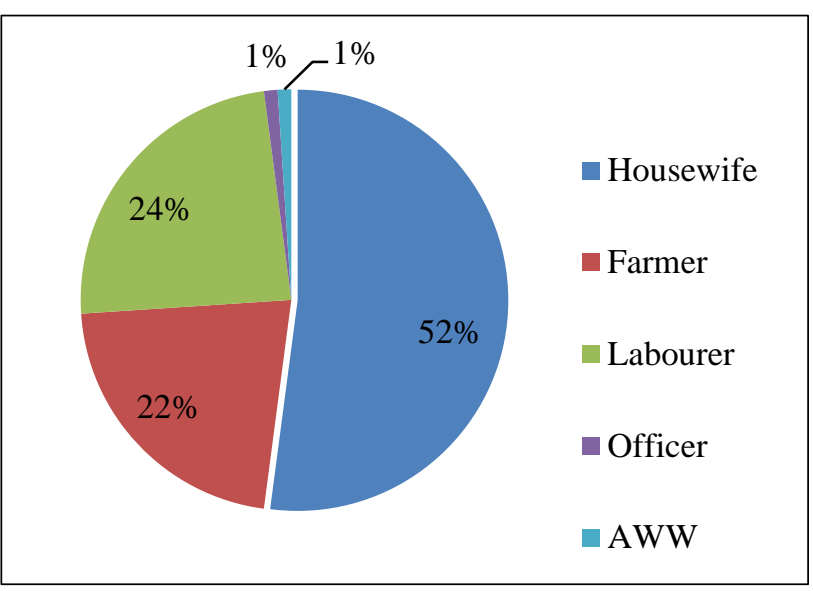

Figure 1: Occupational distribution.
About the relationship status, 46 of the intervened group were married and 2 were widowed, whereas in the control group all 48 were married. The mean parity of the patients was 2.63 with. $36.42 \%$ of the intervened group still engaged in sexual activities, whereas $66.50 \%$ are not engaged presently in sexual activities, as in the control group $29.17 \%$ were still engaged in sexual activities, and $70.83 \%$ were not involved. $14.58 \%$ patients had perception that sexual activities are very important, whereas $70.83 \%$ perceived it as important, rest were in the opinion that sexual activities are slightly important or not important. $89.58 \%$ of the patients were having none of the pre-disposing conditions. $53.19 \%$ of the intervened patients and $45.83 \%$ of control group were diagnosed with DUB. Other diagnosis includes fibrosis - intervened $(21.28 \%)$ and control $(29.17 \%)$, and prolapsed uterus - 
intervened (17.02\%) and control (14.58\%). $81.25 \%$ of intervened patients, and $89.58 \%$ of control group were unaware of the approach of the surgery and $93.75 \%$ patients did not know whether there was associated oophorectomy performed (Table 2).

Table 2: Pre-operative evaluation.

\begin{tabular}{|c|c|c|c|c|}
\hline Variables & Intervention group $\mathbf{A}$ & Study group B & $\mathbf{A}(\%)$ & B $(\%)$ \\
\hline \multicolumn{5}{|l|}{ Sexual status } \\
\hline Still engage in activities & 17 & 14 & 35.42 & 29.17 \\
\hline No longer engage & 30 & 34 & 62.50 & 70.83 \\
\hline Never & 1 & & 2.08 & \\
\hline \multicolumn{5}{|c|}{ Importance of sexual activities } \\
\hline Very important & 8 & 6 & 16.67 & 12.50 \\
\hline Important & 33 & 35 & 68.75 & 72.92 \\
\hline Slightly important & 4 & 3 & 8.33 & 6.25 \\
\hline Not important & 3 & 4 & 6.25 & 8.33 \\
\hline \multicolumn{5}{|l|}{ Predisposed condition } \\
\hline $\mathrm{DM}$ & 1 & 4 & 2.08 & 8.33 \\
\hline HTN & 4 & 1 & 8.33 & 2.08 \\
\hline None & 43 & 43 & 89.58 & 89.58 \\
\hline \multicolumn{5}{|l|}{ Diagnosis } \\
\hline DUB & 25 & 22 & 53.19 & 45.83 \\
\hline Fibroid & 10 & 14 & 21.28 & 29.17 \\
\hline Adenomyosis & 2 & 3 & 4.26 & 6.25 \\
\hline Prolapsed uterus & 8 & 7 & 17.02 & 14.58 \\
\hline PID & & 1 & 0 & 2.08 \\
\hline Ovarian cyst & 2 & 1 & 4.26 & 2.08 \\
\hline \multicolumn{5}{|l|}{ Approach for surgery } \\
\hline Vaginal & 6 & 3 & 2.50 & 6.25 \\
\hline Abdominal & 3 & 2 & 6.25 & 4.17 \\
\hline Don’t know & 39 & 43 & 81.25 & 89.58 \\
\hline \multicolumn{5}{|l|}{ Associated oophorectomy } \\
\hline Yes & 2 & 0 & 4.17 & 0 \\
\hline No & 1 & 3 & 2.08 & 6.25 \\
\hline Don't know & 45 & 45 & 93.75 & 93.75 \\
\hline
\end{tabular}

$83.33 \%$ patients reported that the presence of uterus is important and for $89.58 \%$ patients, absence of uterus post-surgery was acceptable. $72.92 \%$ of intervened group and $60.42 \%$ of the control group were okay about the surgery. $27.08 \%$ of intervened group and $39.58 \%$ of control group were anxious or frightened about the surgery. $100 \%$ patients had support of their husband and $100 \%$ patients were ready for the surgery. As from above there was no variation in the baseline variables.

96 women reporting to the Gynaecology ward of Department of Obstetrics and Gynaecology of a rural tertiary care centre of Central India for hysterectomy operation were randomly selected keeping in mind all the inclusion and exclusion criteria laid down for the study.

Of all the included women, $48.96 \%$ women had DUB, $25 \%$ had fibroids, $15.63 \%$ had prolapsed uterus and the rest had few other benign conditions.
Mean age of the patients was 46 years in intervention group and 47.5 years in control group, mean age of menarche was 14.11 and that of menopause was 49.81 years.

Out of 96 patients only 19 were post-menopausal. $52.08 \%$ of women were house wives, with mean education of $6^{\text {th }}$ standard of schooling.

Patients being from rural background were not so open about their sexual status, $70.83 \%$ patients reported "no longer engaged" in sexual activities, but $85.42 \%$ thought sexual relationship is important out of which $14.58 \%$ reported sexual relationship as "very important."

Around $85 \%$ of the patients were unaware of the approach of the surgery whether vaginal or abdominal and $93.75 \%$ patients were unaware of associated oophorectomy. 
For about $68 \%$ of the patients, the outcome of the surgery i.e. removal of uterus was acceptable, they were not considerate about the hormonal impact of the surgery, which signifies that basic knowledge is missing and has to imparted at grass root level.

Most of the patients (98\%) were had a supportive companion with them throughout the procedure and recovery. About $98 \%$ of the patients were satisfied by the procedure and $95 \%$ were relieved of the presenting symptoms.

\section{Post-operative perception}

Post-operation, 47 of the intervened patients and all the patients of control group were satisfied with the surgery, statistically insignificant; fisher's exact of 1. For 20 intervened patients and 6 patients of control group were very acceptable with the fact that the uterus was no longer present in the body post-surgery, statistically significant; fisher's exact of 0.001. 45 of the intervened group were not feeling depressed whereas 19 patients of the control group were feeling depressed, statistically significant; fisher's exact of 0.0005. 46 of the intervened group were not feeling anxious whereas 24 patients of the control group were feeling anxious, statistically significant; fisher's exact of 0.0005 . When they were asked about are they no longer feeling like women, all the patients in the intervened group did not have any such perception, whereas 10 patients of control group felt that deprivation, statistically significant with fisher's exact of 0.001 . There was statistical significance in the perception about loss of child bearing ability and sudden menopause. (Table 3).

Table 3: Post-operative psychosocial aspects and perception of pain.

\begin{tabular}{|c|c|c|c|c|c|c|c|c|}
\hline \multirow[t]{2}{*}{ Variable } & \multicolumn{2}{|c|}{$\begin{array}{l}\text { Intervention } \\
\mathrm{n}=48\end{array}$} & \multicolumn{2}{|c|}{$\begin{array}{l}\text { Control } \\
n=48\end{array}$} & \multirow[t]{2}{*}{ Pearson $\mathrm{chi}^{2}$} & \multirow[t]{2}{*}{ p value } & \multirow[t]{2}{*}{$\begin{array}{l}\text { Fisher's } \\
\text { exact }\end{array}$} & \multirow[t]{2}{*}{$\begin{array}{l}\text { 1-sided } \\
\text { Fisher's exact }\end{array}$} \\
\hline & Yes & No & Yes & No & & & & \\
\hline Satisfaction & 47 & 1 & 48 & 0 & - & - & 1.000 & 0.500 \\
\hline Perception & 47 & 1 & 46 & 2 & - & - & 1.000 & 0.500 \\
\hline \multicolumn{9}{|c|}{ Psychological impact post-surgery } \\
\hline Depression & 3 & 45 & 19 & 29 & - & - & 0.0005 & 0.0005 \\
\hline Anxiety & 2 & 46 & 24 & 24 & - & - & 0.0005 & 0.0005 \\
\hline $\begin{array}{l}\text { No feeling of } \\
\text { womanhood }\end{array}$ & 0 & 48 & 10 & 38 & - & - & 0.001 & 0.001 \\
\hline $\begin{array}{l}\text { Grief of child } \\
\text { bearing ability }\end{array}$ & 1 & 47 & 2 & 46 & - & - & 0.605 & 0.470 \\
\hline $\begin{array}{l}\text { Grief of loss of } \\
\text { menstrual cycle }\end{array}$ & 0 & 48 & 2 & 46 & - & - & 0.228 & 0.228 \\
\hline \multicolumn{9}{|c|}{ Feeling about removed uterus } \\
\hline Very acceptable & 20 & & 6 & & - & - & & \\
\hline Acceptable & 28 & & 38 & & & & 0.001 & \multirow{2}{*}{-} \\
\hline Not acceptable & 0 & & 4 & & & & & \\
\hline Perception of pain & Yes & No & Yes & No & \multirow[b]{2}{*}{15.88} & \multirow[b]{2}{*}{0.0005} & & \\
\hline Pain in pelvic area & 20 & 28 & 39 & 9 & & & - & - \\
\hline \multicolumn{9}{|l|}{ Frequency of pain } \\
\hline Once a day & 32 & & 6 & & & & \multirow{4}{*}{0.0005} & \multirow{4}{*}{-} \\
\hline Twice a day & 4 & & 22 & & - & - & & \\
\hline Intermittent & 10 & & 15 & & & & & \\
\hline Continuous & 2 & & 5 & & & & & \\
\hline \multicolumn{9}{|l|}{ Quality of pain } \\
\hline Average & 46 & & 24 & & & & \multirow{3}{*}{0.0005} & \\
\hline Worst & 1 & & 19 & & - & \multirow[t]{2}{*}{ - } & & \\
\hline Pain disturbing sleep & 1 & & 5 & & & & & \\
\hline \multicolumn{9}{|l|}{ Troubled by pain } \\
\hline Troubled & 2 & & 19 & & & & \multirow{3}{*}{0.0005} & \\
\hline Not troubled & 45 & & 26 & & - & - & & \\
\hline Not tolerable & 1 & & 3 & & & & & \\
\hline
\end{tabular}




\section{DISCUSSION}

Patients, being from rural areas of India were educated only till the primary level of schooling. This result is consistent with the other studies which stated that hysterectomy appears to be associated with low education, high parity, and a history of multiple miscarriages. The influence of these factors varies depending on the primary indication for the hysterectomy. Due to low level of education patients showed readiness for the surgery $(100 \%)$. Those who had completed only high school education were four times more likely $(95 \%$ confidence interval: $1.8,10.8)$ to have undergone hysterectomy, regardless of the smoking status, BMI, or medical indications for the hysterectomy. ${ }^{10}$ The possible explanations for these findings are that less educated women may delay health seeking behaviour for casual gynecologic problems thereby resulting in hysterectomy as last resort option of treatment or may be are advised hysterectomy as the primary option for treatment by their physicians.

Another impact of low education and rural background is limited knowledge about the approach and associated oophorectomy. Most of the patients $89.58 \%$ were unaware about the approach whether abdominal or vaginal surgery was to be performed, and $93.75 \%$ were unaware whether there was associated oophorectomy. There was no concern about the oophorectomy being done on them and they were not ready for any conservative treatment, instead were reluctant about conservative treatment. There was very less knowledge about the surgery in patients pertaining to the effect of rural background. Another important finding from the study is indication for the surgery, wherein DUB followed by fibroids was the most common indication of hysterectomy, this is in odds with the findings in other studies where most common indication for abdominal approach of the surgery was fibroid uterus (total 39.9\% and out of abdominal $52.7 \%$ ), while for vaginal approach it was uterine prolapse (total $16.3 \%$ and out of vaginal $91.5 \%) .{ }^{11}$

A study in USA also found fibroid $(60 \%)$ to be the most common indication and the $2^{\text {nd }}$ common indication was prolapse (11\%). ${ }^{12}$ The data from Hong Kong, fibroid was a higher proportion of indication for abdominal (73.7\%) and genital prolapse was most common indication (96.2\%) for vaginal hysterectomy. ${ }^{13}$ In Pakistan also the most common reason for hysterectomy was fibroid (33\%) and then was uterine prolapse $(19 \%)$ and DUB in 18 $(12 \%) .{ }^{14}$ In a recent study from Africa again the uterine fibroids were the most common reason for performing hysterectomy (23\%); however there it was followed by DUB (14.9\%). ${ }^{15}$ In a study from Canada, however, the commonest indication of hysterectomy was DUB (26.4\%), followed by fibroid uterus $(16.0 \%) .{ }^{16}$ Another aspect of the study was; only 19 patients out of 98 were post-menopausal.
It is established that hysterectomy has a significant effect on participants' sexual function. ${ }^{12}$ Most of the participants in a study reported that there was a decrease in sexual activity after hysterectomy, while only over $1 / 4^{\text {th }}$ reported normal sexual behaviour. Moreover, a significant reduction in satisfaction about the relationship with spouse or partner in terms of sexual function was observed. Even though, the removal of the ovaries can cause a sudden loss of estrogen and androgen production, which might have an effect on sexual responses, there has been no result regarding the sexual response. Previous retrospective studies have indicated that there is deterioration in sexual functioning post hysterectomy; recent prospective studies have shown a significant improvement. ${ }^{16}$ Even though, hormonal therapy may improve sexual functioning, the effect of a simple hysterectomy on sexuality is very complex and involves various interpersonal factors, cultural beliefs, psychological behaviour, and socioeconomic status. ${ }^{17,18}$ Being from rural area the patients were not very comfortable discussing their sexual status or importance of sexual relationship. So, it was not possible to assess impact of the surgery on the sexual status of the patient as this is a very important aspect to measure recovery in a patient. This therefore is a major drawback of the surgery.

\section{CONCLUSION}

Thus, there was a positive impact of pre-operative education on perceptions about hysterectomy. Women who underwent hysterectomy after receiving preoperative education were content with the results of surgery. Resuscitation in preeclampsia. Acute fetal distress in labour or neonatal nursery admission could not be predicted.

\section{Funding: No funding sources Conflict of interest: None declared \\ Ethical approval: The study was approved by the Institutional Ethics Committee}

\section{REFERENCES}

1. Majumdar A, Saleh S. Psychological aspects of hysterectomy and postoperative care. InHysterectomy InTech. 2012.

2. Rannestad T. Hysterectomy: effects on quality of life and psychological aspects. Best Pract Res Clin Obstet Gynaecol. 2005;19(3):419-30.

3. Singh A, Arora AK. Why Hysterectomy Rates are lower in India. Ind $\mathrm{J}$ Community Med. 2008;33(3):196-7.

4. Wong LP, Arumugam K. Physical, psychological and sexual effects in multi-ethnic Malaysian women who have undergone hysterectomy. J Obstet Gynaecol Res. 2012;38(8):1095-105.

5. Butler GS, Hurley CA, Buchanan KL, SmithVanHorne J. Pre hospital education: effectiveness 
with total hip replacement surgery patients. Patient Educ Couns. 1996;29(2):189-97.

6. Raphael B. Psychiatric aspects of hysterectomy. In: Howells JG, ed: Modern perspectives in the psychiatric aspects of surgery. London: Macmillan; 1978.

7. Green RL Jr. The emotional aspects of hysterectomy. Southern Med J. 1973;66(4), 442-444.

8. Lalinec-Michaud M, Engelmann F. Depression and hysterectomy: a prospective study. Psychosomatics. 1984;25:550-8.

9. Roeske NC. Hysterectomy and other gynaecological surgeries. In: Notman MT, Nadelson CC, eds: The woman patient, medical and psychosocial interfaces: Sexual and reproductive aspects of women's health care. New York: Plenum; 1978;1:217-31.

10. Brett KM, Marsh JV, Madans JH. Epidemiology of hysterectomy in the United States: demographic and reproductive factors in a nationally representative sample. J Women's Health. 1997;6(3):309-16.

11. Pandey D, Sehgal K, Saxena A, Hebbar S, Nambiar J, Bhat RG. An audit of indications, complications, and justification of hysterectomies at a teaching hospital in India. Int $\mathbf{J}$ Reproductive Med. 2014;2014.

12. Broder MS, Kanouse DE, Mittman BS, Bernstein DJ. The appropriateness of recommendations for hysterectomy. Obstet Gynecol. 2000;95(2):199-205.
13. Leung PL, Tsang SW, Yuen PM. An audit on hysterectomy for benign diseases in public hospitals in Hong Kong. Hong Kong Med J. 2007;13(3):187193.

14. Toma WM, Hopman, Gorwill RH. Hysterectomy at a Canadian tertiary care facility: results of a one-year retrospective review. BMC Women's Health. 2004;4:10.

15. El-Toukhy TA, Hefni M, Davies A, Mahadevan S. The effect of different types of hysterectomy on urinary and sexual functions: A prospective study. J Obstet Gynaecol. 2004;24:420-5.

16. Williams RD, Clark AJ. A qualitative study of women's hysterectomy experience. J Womens Health Gend Based Med. 2000;9:S15-25.

17. Polit DF, Beck CT. Nursing research: Principles and methods: Lippincott Williams and Wilkins; 2004.

18. Spalding NJ. A comparative study of the effectiveness of a preoperative education programme for total hip replacement patients. Br J Occup Ther. 1995;58(12):526-31.

Cite this article as: Jain S, Pansare SS. Perceptions of Indian women on hysterectomy. Int J Reprod Contracept Obstet Gynecol 2017;6:4646-51. 